\title{
The Influence of Risk Factors on the Onset and Outcome of Psychosis: what we learned from the GAP Study
}

Murray RM ${ }^{1,2}$, Mondelli $\mathrm{V}^{1}$, Stilo $\mathrm{SA}^{1,3}$, Trotta $\mathrm{A}^{1}$, Sideli $\mathrm{L}^{2}$, Ajnakina $\mathrm{O}^{1}$, Ferraro $\mathrm{L}^{2}$, Vassos $E^{1}$, lyegbe $C^{1}$, Schoeler $T^{1,4}$, Bhattacharrya $S^{1}$, Marques $T^{1}$, Dazzan $\mathrm{P}^{1}$, LopezMorinigo $\mathrm{J}^{1,5}$, Colizzi $\mathrm{M}^{1}$, $\mathrm{O}^{\prime}$ Connor $\mathrm{J}^{1,6}$, Falcone $\mathrm{MA}^{1}$, Quattrone $\mathrm{D}^{1}$, Rodriguez $\mathrm{V}^{1}$, Tripoli $\mathrm{G}^{1,2}$, La Barbera $\mathrm{D}^{2}$, Lacascia $\mathrm{C}^{2}$, Alameda $\mathrm{L}^{1}$, Trotta $\mathrm{G}^{1,7}$, Morgan $\mathrm{C}^{1}$, Gaughran $\mathrm{F}^{1}$, David $\mathrm{A}^{1,8}$ and Di Forti $\mathrm{M}^{1,2}$

${ }^{1}$ Institute of Psychiatry, Psychology and Neuroscience, Department of Psychosis Studies, King's College London, London, UK

${ }^{2}$ Department of Experimental Biomedicine and Clinical Neuroscience, University of Palermo, Palermo, Italy

${ }^{3}$ Division of Psychology and Language Sciences, University College London, London, UK

${ }^{4}$ Department of Psychiatry, Hospital Universitario Fundación Jiménez Díaz, Madrid, Spain

${ }^{5}$ Department of Psychiatry, Universidad Autónoma de Madrid, Madrid, Spain

${ }^{6}$ Department of Neuropsychology, Royal Free London NHS Foundation Trust, Royal Free Hospital, London, UK

${ }^{7}$ Department of Medicine and Surgery, University of Milano Bicocca, Monza, Italy

${ }^{8}$ Institute of Mental Health, University College London, London, UK 


\section{Abstract}

The GAP multidisciplinary study carried out in South London, recruited 410 first episode of psychosis patients and 370 controls; the aim was to elucidate the multiple genetic and environmental factors influencing the onset and outcome of psychosis. The study demonstrated the risk increasing effect of adversity in childhood (especially parental loss, abuse, and bullying) on onset of psychosis especially positive symptoms. Adverse life events more proximal to onset, being from an ethnic minority, and cannabis use also played important roles; indeed, one quarter of new cases of psychosis could be attributed to use of high potency cannabis. The "jumping to conclusions" bias appeared to mediate the effect of lower IQ on vulnerability to psychosis.

We confirmed that environmental factors operate on the background of polygenic risk, and that genetic and environment act together to push individuals over the threshold for manifesting the clinical disorder. The study demonstrated how biological pathways involved in the stress response (HPA axis and immune system) provide important mechanisms linking social risk factors to the development of psychotic symptoms. Further evidence implicating an immune/inflammatory component to psychosis came from our finding of complement dysregulation in FEP. Patients also showed an upregulation of the antimicrobial alpha-defensins, as well as differences in expression patterns of genes involved in NF-KB signaling and Cytokine Production.

Being of African origin not only increased risk of onset but also of a more difficult course of illness. The malign effect of childhood adversity predicted a poorer outcome as did continued use of high potency cannabis. 


\section{Introduction}

South London has been the focus of a series of investigations of psychosis, of which the best known are the Camberwell incidence studies of schizophrenia between 1964 and 1997 (Castle et al., 1998; Boydell et al., 2003), and the Aetiology and Ethnicity in Schizophrenia and Other Psychoses (AESOP) incidence and outcome studies (Fearon et al., 2006; Morgan et al., 2014a, 2014b). Sequential data from 1964 showed a steadily increasing incidence of psychosis, thought to be due to the excess in migrants, and to the increase in cannabis use (Castle et al., 1998; Boydell et al., 2006). The AESOP study demonstrated a higher incidence of psychosis in South London than in Bristol and Nottingham (Kirkbride et al., 2006); derivative studies using similar methodology also showed lower incidence rates in Sao Paulo, Brazil (Menezes et al., 2007) and Palermo, Sicily (Mulè et al., 2017).

However, few data of a biological nature were collected in the above studies, and limited information on recreational drug use. Therefore, we initiated a new casecontrol study of first episode psychosis (FEP) to include the collection of samples for genome-wide association studies (GWAS), and which was, therefore, termed the Genetics and Psychosis (GAP) study. As well as repeating the psychological and social measures from AESOP and collecting information concerning drug use, we examined the hypothalamic pituitary adrenal (HPA) axis and immune response. Thus, the study set out to combine biological, social and drug data into an integrated model of the onset and outcome of psychosis.

The GAP study baseline data collection ran from 2005 till 2010, and thereafter the sample has been followed up until the present; over 37 reports have been published. This paper summarizes the important findings and highlights directions for future research.

\section{Methods}

Patients: We approached all patients aged 18-65 years who presented to the South London and Maudsley (SLaM) NHS Foundation Trust, with FEP. Patients were invited to participate if they met the International Classification of Diseases (ICD)-10 criteria 
for a diagnosis of non-affective (F20-F29) or affective (F30-F33) psychosis (World Health Organization, 1992a). Clinical data were collected using the Schedules for Clinical Assessment in Neuropsychiatry (SCAN) (World Health Organization, 1992b). ICD-10 diagnoses were determined using the OPCRIT checklist (McGuffin et al., 1991). We recruited healthy controls who were representative of the local population. A total of 410 FEP patients, and 370 controls agreed to participate. Further details of the methods can be found in Di Forti et al (Di Forti et al., 2009, 2014) and in the papers cited below.

\section{Social Adversity}

One of the clearest findings was the important role that social adversity plays in psychosis. Compared with controls, FEP patients were three times more likely to have experienced parental loss, and twice as likely to report a long-term separation from a parent in childhood. Parental separation, sexual and physical abuse were specifically associated with the 'positive' psychosis dimension, thus confirming previous reports (Ajnakina et al., 2016).

More patients reported having been victims of bullying than community controls (Trotta et al., 2013). Interestingly, there was an association between bullying victimization and psychosis-like experiences amongst controls, suggesting an aetiological continuum underlying psychotic phenomena both in the general population and in the clinic.

Patients were also more likely to show two or more markers of social disadvantage in adulthood (living alone, being single, unemployed), not only at first contact with psychiatric services but also up to 5 years prior to first contact (Stilo et al., 2013, 2017), with evidence of cumulative effect. Patients had also experienced more stressful life events close to psychosis onset, and subjectively felt more stressed than healthy controls (Mondelli et al., 2010a). Childhood adversities were associated with subsequent cannabis use (Sideli et al., 2015) but not with cognitive functioning (Sideli et al., 2014). 


\section{Hypothalamic-Pituitary-Adrenal axis and Immune markers of stress}

In order to understand the mechanisms linking social adversity to psychosis, we investigated the hypothalamic-pituitary-adrenal (HPA) axis and the peripheral immune system. FEP patients with less than two weeks of antipsychotic treatment had higher diurnal cortisol levels than healthy controls. The difference was not present in patients with longer duration of antipsychotic treatment, implying that antipsychotics may normalize raised cortisol levels.

The cortisol awakening response, a marker of how the HPA axis reacts to stress, was blunted in patients (Mondelli et al., 2010a); this was unrelated to antipsychotics. There was a divergent effect of childhood abuse on the HPA axis in FEP and controls. Following exposure to such abuse, a blunted cortisol awakening response and less reactive HPA axis may represent one of the biological pathways to psychosis (Ciufolini et al., 2019). This low cortisol awakening response was associated with worse cognitive functioning, in particular a more severe deficit in verbal memory and processing speed (Aas et al., 2011).

FEP patients showed increased serum levels of inflammatory markers such as tumornecrosis-factor (TNF)-alpha and interleukin (IL)-1alpha (Di Nicola et al., 2013); TNFalpha levels were particularly high in those patients with a history of childhood trauma suggesting early traumatic experience can facilitate increased adulthood inflammation. Another inflammatory marker, C reactive protein (Hepgul et al., 2012), showed higher serum levels in patients with experience of childhood sexual abuse than both healthy controls and patients without childhood sexual abuse. Further evidence implicating an immune/inflammatory component to psychosis came from our finding of compliment dysregulation in FEP (Kopczynska et al., 2019); complement is, of course, a key driver of inflammation.

Interestingly, increased levels of the pro-inflammatory cytokine IL-6, as well as low levels of the neurotrophic factor BDNF, were associated with smaller left hippocampal volume (Mondelli et al., 2011). High levels of cortisol during the day were also 
associated with smaller left hippocampal volumes (Mondelli et al., 2010b). Indeed, diurnal cortisol, IL-6 and BDNF all independently affected hippocampal volume in FEP (Mondelli et al., 2011). Thus, the excessive HPA and immune responses to stress around the onset of psychosis may contribute to the decrease in hippocampal volume observed over this period.

\section{Cannabis use}

It is now well established that cannabis use can increase the risk of psychosis (Murray et al., 2013; Di Forti et al., 2015), although the mechanism remains unclear (Luizi et al, 2008; Murray et al, 2016). The GAP study was the first to show the importance of the pattern of cannabis use (Di Forti et al., 2009), and that people who used a type of cannabis with high concentration of Delta-9-Tetrahydrocannabinol (THC) were at almost 3 times greater risk of suffering from a psychotic disorder, rising to over 5 times, if they used it daily, compared with those who never used; they also experienced psychosis onset on average 6 years earlier than never users (Di Forti et al., 2014).

The association between use of high potency cannabis and risk of psychosis was not explained by differences in socio-demographic characteristics, other drug use, or genetic load for psychosis (Di Forti et al., 2015). Indeed, we calculated that in South London, the proportion of first- episode psychosis attributable to use of high potency cannabis was 24\% (Di Forti et al., 2015).

A number of studies have reported better cognitive performance in those patients with psychosis who used cannabis, compared with those who had not. This is surprising as cannabis can impair cognition in healthy subjects. The GAP study offered a possible explanation by showing that FEP patients who had smoked cannabis had not only a higher current IQ but also a higher premorbid IQ than patients who had never used cannabis (Ferraro et al., 2013); this difference was not found among controls; cannabis appears to play a role in provoking psychosis in people who were less neurodevelopmentally impaired than is generally the case in psychosis. One 
possible mechanism for this could be the disturbed microstructural organization of the corpus callosum which we found associated with use of high potency cannabis (Rigucci et al., 2016).

An analysis of reasons for use of cannabis found little evidence in support of a 'selfmedication' motive (Kolliakou et al., 2015). Interestingly, FEPs were more likely to report both 'bad' (i.e. exacerbation of psychotic like experiences) and 'enjoyable' (i.e. feeling high, full of ideas) experiences than controls when using high-potency cannabis (Bianconi et al., 2016). In this way, greater pleasurable effects of cannabis may reinforce its continued use in those who become psychotic, despite the concomitant exacerbation of psychotic symptoms.

\section{Candidate genes}

We replicated a report of an interaction between the AKT1 (rs2494732) genotype and cannabis use (Di Forti et al., 2012) in conveying vulnerability to psychosis; similarly we found evidence of interaction between cannabis use and variation at the DRD2 gene (Colizzi et al., 2015). These findings that individual genes may influence susceptibility to cannabis-induced psychosis must remain tentative till further confirmed. There was no evidence of interaction between COMT Val158Met, AKT1, or DRD2 polymorphisms and exposure to childhood adversity in relation to psychosis onset (Trotta et al., 2018).

\section{Whole-genome approaches}

We calculated the polygenic risk score for schizophrenia (PRS-Sz), which summarises genome-wide data into a single variable that measures genetic liability to the disorder (Vassos et al., 2017). We found PRS-Sz to be a powerful predictor of case-control status in European individuals (9.4\% of the variance explained), but not in individuals of African ancestry. Interestingly, PRS distinguished cases who acquired a schizophrenia diagnosis from those with other psychotic disorders such as delusional disorder, affective psychosis or brief psychotic episode. This was the first study to 
demonstrate the potential clinical utility of PRS, and included a replication in a sample of patients with chronic schizophrenia.

We then examined the interplay between PRS and childhood adversity in FEP but did not find evidence of interaction (Trotta et al., 2016a). We also examined the interplay of childhood adversity and familial risk, using family history as a proxy of the overall genetic loading to psychosis (Trotta et al., 2015). Again we found no interaction between the two risk factors. We concluded that genetic liability whether measured by family history or molecular means, and childhood adversity contribute independently to the aetiology of psychosis.

\section{Gene Expression:}

When comparing the blood transcriptome of FEP patients and healthy controls, we found evidence for multiple disrupted pathways, primarily related to oxidative stress and immune signaling. We notably found an upregulation of the antimicrobial alpha-defensins in FEP patients, as well as differences in expression patterns of genes involved in NF-KB signaling and Cytokine Production. (Leirer et al., 2019). These effects could not be explained by anti-psychotic medication, and in fact medication correlated with a reduction in the magnitude of changes between FEP patients and controls.

\section{Psychological Mechanisms}

We focused on the "jumping to conclusions" (JTC) data-gathering bias. Half of the FEPs jumped to conclusions on at least one of tasks proposed, compared with $25 \%$ of controls (Falcone et al., 2015a). JTC was associated with severity of clinical delusions, and with worse neuropsychological functioning in both cases and controls. Each point decrease in IQ increased the likelihood of JTC by around $4 \%$. This finding suggests that JTC operates to mediate the effect of lower IQ on vulnerability to psychosis.

All those with persisting delusions at 12 months jumped to conclusions either at baseline or follow-up, compared to half of those with no, or amenable, delusions (Falcone et al., 2015b). Over the 4 years following onset, JTC predicted longer admissions, more compulsory admissions and police involvement (Rodriguez et al., 
2018).

\section{Outcome}

Biological markers: Both a blunted cortisol awakening response and increased levels of inflammatory markers, such as IL-6 and interferon (IFN)-gamma, at baseline predicted poor response at three months (Mondelli et al., 2015) . Worse metabolic and inflammatory status onset, characterized by high $\mathrm{C}$ reactive protein, high body mass index and high triglycerides levels, predicted poor treatment response at 1-year follow-up (Nettis et al., 2019).

MRI examination also showed that poor treatment response three months after onset was predicted by abnormal gyrification (Palaniyappan et al., 2013) and decreased white matter integrity (Marques et al., 2014).

Risk Factors: Black patients had longer inpatient stays, higher rates of compulsory admissions and increased instances of police involvement during re-admission compared with patients of White British ethnicity during the first 5 years of illness (Ajnakina et al, 2017).

Childhood physical abuse was associated with almost 3-fold increased odds of not being in a relationship at 1-year follow-up compared to non-abused patients (Trotta et al, 2016b). Greater service utilisation over 5 years (Ajnakina et al, 2018) was predicted by institutional care and by death of a biological parent; parental separation was associated with non-compliance with medication.

Lack of insight at baseline predicted symptom severity at long-term follow-up (O'Connor et al., 2013, 2017). Previous suicide attempts, and depression both of which were linked with baseline insight levels, predicted subsequent suicidal behavior (Lopez-Morinigo et al., 2019).

Cannabis use: Those who stopped using cannabis had the most favourable course of illness (Colizzi et al., 2016; Schoeler et al., 2016a). In contrast, those who continued 
using high-potency cannabis daily showed fewer months until a relapse occurred, more relapses, and required more intensive psychiatric care (Schoeler et al., 2016a, 2016b, 2017a, 2017b). Continued use of cannabis was also associated with poorer adherence to prescribed antipsychotic medications but this link did not fully explain the adverse long-term outcomes seen in cannabis-using FEPs (Colizzi et al., 2016; Schoeler et al., 2016a, 2016b, 2017a, 2017b).

Treatment Resistance: Five years after onset, one third of patients who initially received a diagnosis of schizophrenia met criteria for Treatment Resistance. $70 \%$ of such patients did not respond to an antipsychotic from their first contact with mental health services for psychosis (Lally et al., 2016), which fits with the idea that there may be a distinctive poor outcome subgroup which shows no striatal dopaminergic excess (Demjaha et al., 2012). A study using the ten-year outcome data from the AESOP similarly reported two types of treatment resistance (Demjaha et al., 2017). This and the evidence noted above that abnormal gyrification and white matter integrity are associated with poor treatment response, raises the question of whether this is a neurodevelopmentally damaged group. The other $30 \%$ of the treatment resistant patients initially responded to antipsychotics, before becoming resistant, suggesting that the loss of response in these cases could be due to the emergence of dopamine receptor supersensitivity (Murray et al., 2016).

\section{Conclusions}

The GAP study demonstrated the influence of number of different risk factors on the onset of psychosis. It further clarified the effect of adversity in childhood (especially parental loss, abuse, and bullying) reported in the AESOP study, and associated it particularly with development of positive psychotic symptoms. As in the Camberwell Functional Psychosis Study (Bebbington et al, 1993), we found that adverse life events proximal to onset increased risk. And as in all our previous studies in South London, being from an ethnic minority especially of African ancestry, also played an important role. In addition, about one quarter of new cases of psychosis could be attributed to daily use of high potency cannabis. A subsequent study carried out by Di Forti et al (2019) showed that this proportion had risen to $30 \%$, possibly due to the further 
increase in the potency of the available cannabis.

Biological pathways involved in the stress response (HPA axis and immune system) provide important mechanisms linking risk factors to the development of psychotic symptoms The GAP study confirms that environmental factors operate on the background of polygenic risk for schizophrenia but our preliminary evidence does not show gene-environment interaction; for example, genetic loading and childhood adversity appeared to act in a simple additive manner to propel the individual over the threshold for manifestation of psychosis.

It is not surprising that risk factors for onset such as adversity, ethnicity, and cannabis use also played a role in determining the outcome. if an individual has suffered sufficient adversity to contribute to onset of psychosis, then one can understand how this malign effect can carry over to influence outcome. On the other hand, if the aetiological factor can be removed, e.g. by ceasing high potency cannabis use, then outcome can be much better. The fact that black patients still have a worse outcome than their white counterparts should alarm British policy makers given the huge attention that this issue has received in the UK over more than two decades.

Several of the biological findings in GAP have subsequently been confirmed. Other studies have replicated the presence of a blunted cortisol awakening response in patients with first episode psychosis and schizophrenia, as also supported by a recent meta-analysis (Berger et al., 2016). Increased levels of inflammatory markers have been reported by subsequent studies in first episode psychosis (Zajkowska and Mondelli, 2014; Corsi-Zuelli et al 2019; Pillinger et al., 2019). To our knowledge, no subsequent study has yet been published investigating the association between such stress biomarkers and cognitive function or hippocampal volume specifically in first episode psychosis.

The polygenic risk score for schizophrenia, although a useful measure of overall genetic loading, is perhaps too non-specific to elucidate interactions with individual environmental factors. A larger study might enable examination of specific gene sets, for example, whether endocannabinoid genes influence susceptibility to cannabis- 
induced psychosis, or whether genes influencing the striatal dopamine response render certain individuals exposed to childhood adversity especially prone to psychosis.

The GAP study also exemplifies the limitations of FEP studies carried out in one location. Firstly, although we confirmed the main risk factors for psychosis which we had found in our previous studies in South London, it is likely that different risk factors for psychosis play a role of varying importance in different countries, depending, for example, on the extent of migration or the availability of high potency cannabis. Secondly, studies from one centre are likely to be too small to enable exploration of how risk factors co-occur or interact with each other. Similarly, although we found a number of predictors of poor outcome, the study did not have sufficient power to examine their joint effect.

\section{Implications for the future}

The last two decades have seen the elucidation of many of the contributing environmental causes of psychosis; the GAP study has contributed to this advance. However, it remains unclear if, and how, such environmental risk factors interact with each other or with susceptibility genes to cause the disorder, or whether their combined effect is just the sum of their individual effects. Furthermore, we know little of the pathogenic pathways linking risk factors to expression of disorder. Larger multicenter first episode studies which span different countries and continents are now necessary. Such studies should include not only examination of genetic and biological pathways but also follow-up over a number of years. Such expensive studies which are common in medicine are now required in psychosis research.

Now that we have some knowledge of individual risk factors for psychosis, then an obvious next step is to attempt to limit exposure to these factors. The findings concerning cannabis are of particular importance particularly because of the increasing availability in many countries of high potency cannabis. It is time to develop a public health strategy for the prevention of psychosis addressing potentially 
modifiable risk factors such as cannabis us.

\section{References}

Aas, M., Dazzan, P., Mondelli, V., Toulopoulou, T., Reichenberg, A., Di Forti, M., Fisher, H.L., Handley, R., Hepgul, N., Marques, T.R., Miorelli, A., Taylor, H., Russo, M., Wiffen, B., Papadopoulos, A., Aitchinson, K.J., Morgan, C., Murray, R.M., Pariante, C.M., 2011. Abnormal cortisol awakening response predicts worse cognitive function in patients with first-episode psychosis. Psychol. Med. 41 (3), 463-476.

Ajnakina, O., Trotta, A., Oakley-Hannibal, E., Di Forti, M., Stilo, S.A., Kolliakou, A., Gardner- Sood, P., Gaughran, F., David, A.S., Dazzan, P, Pariante, C.M., Mondelli, V., Morgan, C., Vassos, E., Murray, R.M., Fisher, H.L., 2016. Impact of childhood adversities on specific symptom dimensions in first-episode psychosis. Psychol. Med. 46 (2), 317-326.

Ajnakina, O., Lally, J., Di Forti, M., Kolliakou, A., Gardner-Sood, P., Lopez-Morinigo, J., Dazzan, P., Pariante, C.M., Mondelli, V., MacCabe, J., David, A.S., Gaughran, F., Murray, R.M., Vassos, E., 2017. Patterns of illness and care over the 5 years following onset of psychosis in different ethnic groups; the GAP-5 study. Soc. Psychiatry Psychiatr. Epidemiol. 52 (9), 1101-1111.

Ajnakina, O., Trotta, A., Di Forti, M., Stilo, S.A., Kolliakou, A., Gardner-Sood, P., LopezMorinigo, J., Gaughran, F., David, A.S., Dazzan, P., Pariante, C.M., Mondelli, V., Murray, R.M., Fisher, H.L., 2018. Different types of childhood adversity and 5 year outcomes in a longitundinal cohort of first episode psychosis patients. Psychiatry Res. 269: 199-206.

Bebbington, P., Wilkins, S., Jones,P., Foerster, A., Murray, R.M., Toone, B., and Lewis, S. 1993. Life Events and Psychosis. Br. J. Psychiatry, 179, 72-79

Berger M, Kraeuter A,K., Romanik D., Malouf P., Amminger GP., Sarnya Z., 2016. Cortisol awakening response in patients with psychosis: Systematic 
review and meta-analysis. Neuroscience \& Biobehavioral Reviews, 68, 157166

Bianconi, F., Bonomo, M., Marconi, A., Kolliakou, A., Stilo, S.A., Iyegbe, C., Gurillo Muñoz, P., Homayoun, S., Mondelli, V., Luzi, S., Dazzan, P., Prata, D., La Cascia, C., O'Connor, J., David, A., Morgan, C., Murray, R.M., Lynskey, M., Di Forti, M., 2016. Differences in cannabis-related experiences between patients with a first episode of psychosis and controls. Psychol. Med. 46 (5), 995-1003.

Boydell, J., Van Os, J., Lambri, M., Castle, D., Allardyce, J., McCreadie, R.G., Murray, R.M., 2003. Incidence of schizophrenia in south-east London between 1965 and 1997. Br. J. Psychiatry 182: 45-49.

Boydell, J., Van Os, J., Caspi, A., Kennedy, N., Giouroukou, E., Fearon, P., Farrell, M., Murray, R.M., 2006. Trends in cannabis use prior to first presentation with schizophrenia, in South-East London between 1965 and 1999. Psychol. Med. 36 (10), 1441-1446

Castle, D., Wessely, S., Van os, J., Murray, R.M., 1998. Psychosis in the Inner City: the Camberwell First Episode Study. Hove. Maudsley Monoraph.

Ciufolini, S., Gayer-Anderson, C., Fisher, H. L., Marques, T. R., Taylor, H., Di Forti, M., Zunszain, P., Morgan, C., Murray, R.M., Pariante, C.M., Dazzan, P., 2019. Cortisol awakening response is decreased in patients with first-episode psychosis and increased in healthy controls with a history of severe childhood abuse. Schizophr. Res. 205, 38-44.

Colizzi, M., Iyegbe, C., Powell, J., Ursini, G., Porcelli, A., Bonvino, A., Taurisano, P., Romano, R., Masellis, R., Blasi, G., Morgan, C., Aitchison, K., Mondelli, V., Luzi, S., Kolliakou, A., David, A., Murray, R.M., Bertolino, A., Di Forti, M., 2015. Interaction Between Functional Genetic Variation of DRD2 and Cannabis Use on Risk of Psychosis. Schizophr. Bull. 41 (5), 1171-1182.

Colizzi, M., Carra, E., Fraietta, S., Lally, J., Quattrone, D., Bonaccorso, S., Mondelli, V., Ajnakina, O., Dazzan, P., Trotta, A., Sideli, L., Kolliakou, A., Gaughran, F., Khondoker, M., David, A.S., Murray, R.M., MacCabe, J.H., Di Forti, M., 2016. Substance use, medication adherence and outcome one year following a first episode of psychosis. Schizophr. Res. 170 (2-3), 311-317.

Corsi-Zuelli F, Loureiro CM, Shuhama R, Fachim HA., 2019 Cytokine profile in first- 
episode psychosis, unaffected siblings and community-based controls: the effects of familial liability and childhood maltreatment. Psychological Medicine, May 8:1-9 on line.

Demjaha, A., Murray, R.M., McGuire, P.K., Kapur, S., Howes, O.D., 2012 Dopamine Synthesis Capacity in Patients With Treatment-Resistant Schizophrenia. Am. J. Psychiatry 169 (11), 1203-1210.

Demjaha, A., Lappin, J.M., Stahl, D., Patel, M.X., MacCabe, J.H., Howes, O.D., Heslin, M., Reininghaus, U.A., Donoghue, K., Lomas, B., Charalambides, M., Onyejiaka, A., Fearon, P., Jones, P., Doody, G., Morgan, C., Dazzan, P., Murray, R.M., 2017. Antipsychotic treatment resistance in first-episode psychosis: prevalence, subtypes and predictors. Psychol. Med. 47 (11), 1981-1989.

Di Forti, M., Morgan, C., Dazzan, P., Pariante, C.M., Mondelli, V., Marques, T.R., Handley, R., Luzi, S., Russo, M., Paparelli, A., Butt, A., Stilo, S.A., Wiffen, B., Powell, J., Murray, R.M., 2009. High-potency cannabis and the risk of psychosis. Br. J. Psychiatry 195 (6), 488-491.

Di Forti, M., Iyegbe, C., Sallis, H., Kolliakou, A., Falcone, M.A., Paparelli, A., Sirianni, M., La Cascia, C., Stilo, S.A., Marques, T.R., Handley, R., Mondelli, V., Dazzan, P., Pariante, C., David, A.S., Morgan, C., Powell, J., Murray, R.M., 2012. Confirmation that the AKT1 (rs2494732) genotype influences the risk of psychosis in cannabis users. Biol. Psychiatry 72 (10), 811-816.

Di Forti, M., Sallis, H., Allegri, F., Trotta, A., Ferraro, L., Stilo, S.A., Marconi, A., La Cascia, C., Marques, T.R., Pariante, C.M., Dazzan, P., Mondelli, V., Paparelli, A., Kolliakou, A., Prata, D., Gaughran, F., David, A.S., Morgan, C., Stahl, D., Khondoker, M., MacCabe, J.H., Murray, R.M., 2014. Daily use, especially of high-potency cannabis, drives the earlier onset of psychosis in cannabis users. Schizophr. Bull. 40 (6), 1509-1517.

Di Forti, M., Marconi, A., Carra, E., Fraietta, S., Trotta, A., Bonomo, M., Bianconi, F., Gardner-Sood, P., O'Connor, J., Russo, M., Stilo, S.A., Marques, T.R., Mondelli, V., Dazzan, P., Pariante, C.M., David, A.S., Gaughran, F., Atakan, Z., lyegbe, C., Powell, J., Morgan, C., Lynskey, M., Murray, R.M., 2015. Proportion of patients in south London with first-episode psychosis attributable to use of high potency cannabis: a case-control study. Lancet Psychiatry 2 (3), 233-238 
Di Forti, M., Quattrone D., FreemanTP., Tripoli G., Gayer-Anderson C., Qicgley H., Rodrigiuez V., Jongsma H., Ferraro L., La Cascia C., La Barbera D., Taricone I., Berardi D, Szoke A., Arango C., Tortelli A., Velthorst E., Bernardo M., Del-Ben CM., Menezes PR., Selten JP., Jones PB., Kirkbride JB., Rutten. BPF., De Haan. L., Sham PC., Van Os J., Lewis CM., Lynskey M., Morgan. C., Murray RM The contribution of cannabis use to variationin the incidence of psychosis across Europe. Lancet Psychiatry, 6, 5, 427-436

Di Nicola, M., Cattaneo, A., Hepgul, N., Di Forti, M., Aitchison, K.J., Janiri, L., Murray, R.M., Dazzan P., Pariante, C.M., Mondelli, V., 2013. Serum and gene expression profile of cytokines in first-episode psychosis. Brain Behav. Immun. 31, 90-95. Falcone, M.A., Murray, R.M., Wiffen, B.D.R., O'Connor, J.A., Russo, M., Kolliakou, A., Stilo, S., Taylor, H., Gardner-Sood, P., Paparelli, A., Jichi, F., Di Forti, M., David, A.S., Freeman, D., Jolley, S., 2015a. Jumping to Conclusions, Neuropsychological Functioning, and Delusional Beliefs in First Episode Psychosis. Schizophr. Bull. 41 (2), 411-418.

Falcone, M.A., Murray, R.M., O’Connor, J.A., Hockey, L.N., Gardner-Sood, P., Di Forti, M., Freeman, D., Jolley, S., 2015b. Jumping to conclusions and the persistence of delusional beliefs in first episode psychosis. Schizophr. Res. 165 (2-3), 243246.

Fearon, P., Kirkbride, J.B., Morgan, C., Dazzan, P., Morgan, K., Lloyd, T., Hutchinson, G., Tarrant, J., Fung, W.L., Holloway, J., Mallett, R., Harrison, G., Leff, J., Jones, P.B., Murray, R.M., AESOP Study Group, 2006. Incidence of schizophrenia and other psychoses in ethnic minority groups: results from the MRC AESOP Study. Psychol Med. 36 (11), 1541-1550.

Ferraro, L., Russo, M., O’Connor, J., Wiffen, B.D., Falcone, M.A., Sideli, L., GardnerSood, P., Stilo, S., Trotta, A., Dazzan, P., Mondelli, V., Taylor, H., Friedman, B., Sallis, H., La Cascia, C., La Barbera, D., David, A.S., Reichenberg, A., Murray, R.M., Di Forti, M., 2013. Cannabis users have higher premorbid IQ than other patients with first onset psychosis. Schizophr. Res. 150 (1), 129-135.

Hepgul, N., Pariante, C.M., Dipasquale, S., Di Forti, M., Taylor, H., Marques, T.R., Morgan, C., Dazzan,P., Murray, R.M., Mondelli, V., 2012. Childhood 
maltreatment is associated with increased body mass index and increased Creactive protein levels in first-episode psychosis patients. Psychol. Med. 42 (09), 1893-1901.

Kirkbride, J.B., Fearon, P., Morgan, C., Dazzan, P., Morgan, K., Tarrant, J., Lloyd, T., Holloway, J., Hutchinson, G., Leff, J.P., Mallett, R.M., Harrison, G.L., Murray, R.M., Jones, P.B., 2006. Heterogeneity in incidence rates of schizophrenia and other psychotic syndromes: findings from the 3-center AeSOP study. Arch. Gen. Psychiatry 63 (3), 250-258.

Kolliakou, A., Castle, D., Sallis, H., Joseph, C., O'Connor, J., Wiffen, B., GayerAnderson, C., McQueen, G., Taylor, H., Bonaccorso, S., Gaughran, F., Smith, S., Greenwood, K., Murray, R.M., Di Forti, M., Atakan, Z., Ismail, K., 2015. Reasons for cannabis use in first-episode psychosis: Does strength of endorsement change over 12 months? Eur. Psychiatry 30 (1), 152-159.

Kopczynska, M., Zelek, W., Touchard, S., Gaughran, F., Di Forti, M., Mondelli, V., Murray, R.M., O'Donovan, M., Morgan, B.P., 2019. Complement system biomarkers in first episode psychosis. Schizophr. Res. 204, 16-22.

Lally, J., Ajnakina, O., Di Forti, M., Trotta, A., Demjaha, A., Kolliakou, A., Mondelli, V., Marques, T.R., Pariante, C.M., Dazzan, P., Shergil, S.S., Howes, O.D., David, A.S., MacCabe, J.H., Gaughran, F., Murray, R.M., 2016. Two distinct patterns of treatment resistance: clinical predictors of treatment resistance in firstepisode schizophrenia spectrum psychoses. Psychol. Med. 46 (15), 3231-3240. Leirer, D.J., Iyegbe, C.O., Di Forti, M., Patel, H., Carra, E., Fraietta, S., Colizzi, M., Mondelli, V., Quattrone, D., Lally, J., Ajnakina, O., Lee, S.H., Curtis, C.J., Breen, G., Pariante, C., Aitchinson, K., Dazzan, P., Murray, R.M., Dobson, R.J.B., Newhouse S.J., 2019. Differential gene expression analysis in blood of first episode psychosis patients. Schizophr. Res. 209, 88-97.

Lopez-Morinigo, J.D., Di Forti, M., Ajnakina, O., Wiffen, B.D., Morgan, K., Doody, G.A., Jones, P.B., Ayesa-Arriola, R., Canal-Rivero, M., Crespo-Facorro, B., Murray, R.M., Dazzan, P., Morgan, C., Dutta R., David, A.S., 2019. Insight and risk of suicidal behaviour in two first-episode psychosis cohorts: Effects of previous suicide attempts and depression. Schizophr. Res. 204, 80-89. 
Luzi, S., Morrison, P D., Powell, J.,Di Forti M, Murray R. 2008. What is the Mechanism whereby Cannabis Use increases Risk of Psychosis? Neurotoxicity Research, $14,2-3,105-112$

Marques, T.R., Taylor, H., Chaddock, C., Dell'acqua, F., Handley, R., Reinders, A.A., Mondelli, V., Bonaccorso, S., Di Forti, M., Simmons, A., David, A.S., Murray, R.M., Pariante, C.M., Kapur, S., Dazzan, P., 2014. White matter integrity as a predictor of response to treatment in first episode psychosis. Brain 137, 172182.

McGuffin, P., Farmer, A., Harvey, I., 1991. A polydiagnostic application of operational criteria in studies of psychotic illness: Development and reliability of the OPCRIT system. Arch. Gen. Psychiatry 48 (8), 764-770.

Menezes, P.R., Scazufca, M., Busatto, G.F., Coutinho, L.M.S., Mcguire, P.K., Murray, R.M., 2007. Incidence of first-contact psychosis in São Paulo, Brazil. Br. J. Psychiatry 191 (S51), s102-s106.

Mondelli, V., Dazzan, P., Hepgul, N., Di Forti, M., Aas, M., D'Albenzio, A., Di Nicola, M., Fisher, H., Handley, R., Marques, T.R., Morgan, C., Navari, S., Taylor, H., Papadopoulos, A., Aitchison, K.J., Murray, R.M., Pariante, C.M., 2010a.

Abnormal cortisol levels during the day and cortisol awakening response in first-episode psychosis: The role of stress and of antipsychotic treatment. Schizophr. Res. 116 (2-3), 234-242.

Mondelli, V., Pariante, C.M., Navari, S., Aas, M., D'Albenzio, A., Di Forti, M., Handley, R., Hepgul, N., Marques, T.R., Taylor, H., Papadopoulos, A.S., Aitchison, K.J., Murray, R.M., Dazzan, P., 2010b. Higher cortisol levels are associated with smaller left hippocampal volume in first-episode psychosis. Schizophr. Res. 119 (1-3), 75-78.

Mondelli, V., Cattaneo, A., Murri, M.B., Di Forti, M., Handley, R., Hepgul, N., Miorelli, A., Navari, S., Papadopoulos, A.S., Aitchison, K.J., Morgan, C., Murray, R.M., Dazzan, P., Pariante, C.M. 2011. Stress and inflammation reduce brain-derived neurotrophic factor expression in first-episode psychosis: A pathway to smaller hippocampal volume. J. Clin. Psychiatry 72 (12), 1677-1684.

Mondelli, V., Ciufolini, S., Belvederi Murri, M., Bonaccorso, S., Di Forti, M., Giordano, 
A., Marques, T.R., Zunszain, P.A., Morgan, C., Murray, R.M., Pariante, C.M., Dazzan, P., 2015. Cortisol and Inflammatory Biomarkers Predict Poor Treatment Response in First Episode Psychosis. Schizophr. Bull. 41 (5), 11621170.

Morgan, C., Reininghaus, U., Fearon, P., Hutchinson, G., Morgan, K., Dazzan, P., Boydell, J., Kirkbride, J.B., Doody, G.A., Jones, P.B., Murray, R.M., Craig, T., 2014a. Modelling the interplay between childhood and adult adversity in pathways to psychosis: initial evidence from the AESOP study. Psychol. Med. $44(2), 407-419$.

Morgan, C., Lappin, J., Heslin, M., Donoghue, K., Lomas, B., Reininghaus, U., Onyejiaka, A., Croudace, T., Jones, P.B., Murray, R.M., Fearon, P., Doody, G.A., Dazzan, P., 2014b. Reappraising the long-term course and outcome of psychotic disorders: the AESOP-10 study. Psychol. Med. 44 (13), 2713-2726.

Mulè, A., Sideli, L., Capuccio, V., Fearon, P., Ferraro, L., Kirkbride, J.B., La Cascia, C., Sartorio, C., Seminerio, F., Tripoli, G., Di Forti, M., La Barbera, D., Murray, R.M., 2017. Low incidence of psychosis in Italy: confirmation from the first epidemiological study in Sicily. Soc. Psychiatry Psychiatr. Epidemiol. 52 (2).

Murray, R.M., Paparelli, A., Morrison, P.D., Marconi, A., Di Forti, M., 2013. What Can We Learn About Schizophrenia From Studying the Human Model, DrugInduced Psychosis? Am. J. Med. Genent. B Neuropsychiatr. Genet. 162 (7), 661-670.

Murray, R. M., Quattrone, D., Natesan, S., van Os, J., Nordentoft, M., Howes, O., Di Forti, M., Taylor, D., 2016. Should psychiatrists be more cautious about the long-term prophylactic use of antipsychotics? Br. J. Psychiatry 209 (5), 361365.

Murray, R. M., Englund A., Abi-Dhargum A., Lewis DA., Di Forti M., Davies C., Sherif M., McGuire P., D’Souza D C., 2016. Cannabis-associated psychosis: neural substrate and clinical impact. Neuropharmacology, 124, Special Issue, 89-104

Nettis, M.A., Pergola, G., Kolliakou, A., O'Connor, J., Bonaccorso, S., David, A., Gaughran, F., Di Forti, M., Murray, R.M., Marques, T.R., Blasi, G., Bertolino, A., Pariante, C.M., Dazzan, P., Mondelli, V., 2019. Metabolic-inflammatory status 
as predictor of clinical outcome at 1-year follow-up in patients with first episode psychosis. Psychoneuroendocrinology 99, 145-153.

O’Connor, J.A., Wiffen, B., Di Forti, M., Ferraro, L., Joseph, C., Kolliakou, A., Bonaccorso, S., Murray, R.M., David, A.S., 2013. Neuropsychological, clinical and cognitive insight predictors of outcome in a first episode psychosis study. Schizophr. Res. 149 (1-3), 70-76.

O’Connor, J.A., Ellett, L., Ajnakina, O., Schoeler, T., Kolliakou, A., Wiffen, B.D., Falcone, A.M., Di Forti, M., Murray, R.M., Bhattacharyya, S., David, A.S., 2017. Can cognitive insight predict symptom remission in a first episode psychosis cohort? BMC Psychiatry 17 (1), 54.

Palaniyappan, L., Marques, T.R., Taylor, H., Handley, R., Mondelli, V., Bonaccorso, S., Giordano, A., McQueen, G., Di Forti, M., Simmons, A., David, A.S., Pariante, C.M., Murray, R.M., Dazzan, P., 2013. Cortical Folding Defects as Markers of Poor Treatment Response in First-Episode Psychosis. JAMA Psychiatry 70 (10), 1031-1040.

Pillinger T, Osimo EF, Brugger S, Mondelli V, McCutcheon, RA Howes OD 2019 A Meta-analysis of Immune Parameters, Variability, and Assessment of Modal Distribution in Psychosis and Test of the Immune Subgroup Hypothesis Schizophrenia Bulletin 45(5):1120-1133

Rigucci, S., Marques, T.R., Di Forti, M., Taylor, H., Dell'Acqua, F., Mondelli, V., Bonaccorso, S., Simmons, A., David, A.S., Girardi, P., Pariante, C. M., Murray, R.M., Dazzan, P., 2016. Effect of high-potency cannabis on corpus callosum microstructure. Psychol. Med. 46 (4), 841-854.

Rodriguez, V., Ajnakina, O., Stilo, S.A., Mondelli, V., Marques, T.R., Trotta, A., Quattrone, D., Gardner-Sood, P., Colizzi, M., Wiffen, B.D., Dazzan, P., Di Forti, M., Falcone, M.A., David, A.S., Murray, R.M., 2018. Jumping to conclusions at first onset of psychosis predicts longer admissions, more compulsory admissions and police involvement over the next 4 years: the GAP study. Psychol. Med. 5, 1-11. 
Schoeler, T., Petros, N., Di Forti, M., Klamerus, E., Foglia, E., Ajnakina, O., GayerAnderson, C., Colizzi, M., Quattrone, D., Behlke, I., Shetty, S., McGuire, P., David, A.S., Murray, R.M., Bhattacharyya, S., 2016a. Effects of continuation, frequency, and type of cannabis use on relapse in the first 2 years after onset of psychosis: an observational study. Lancet Psychiatry 3 (10), 947-953.

Schoeler, T., Petros, N., Di Forti, M., Pingault, J.B., Klamerus, E., Foglia, E., Small, A., Murray, R.M., Bhattacharyya, S., 2016b. Association Between Continued Cannabis Use and Risk of Relapse in First-Episode Psychosis: A QuasiExperimental Investigation Within an Observational Study. JAMA psychiatry 73 (11), 1173-1179.

Schoeler, T., Petros, N., Di Forti, M., Klamerus, E., Foglia, E., Murray, R.M., Bhattacharyya, S., 2017a. Effect of continued cannabis use on medication adherence. in the first two years following onset of psychosis. Psychiatry Res. $225,36-41$.

Schoeler, T., Petros, N., Di Forti, M., Klamerus, E., Foglia, E., Murray, R.M., Bhattacharyya, S., 2017b. Poor medication adherence and risk of relapse associated with contijued cannabis use in patients with first episode psychosis. Lancet Psychiatry 4 (8), 627-33.

Sideli, L., Fisher, H.L., Murray, R.M., Sallis, H., Russo, M., Stilo, S.A., Paparelli, A., Wiffen, B.D.R., O'Connor, J.A., Pintore, S., Ferraro, L., La Cascia, C., La Barbera, D., Morgan, C., Di Forti, M., 2018. Interaction between cannabis consumption and childhood abuse in psychotic disorders: Preliminary findings on the role of different patterns of cannabis use. Early Interv. Psychiatry 12 (2), 135-142.

Sideli, L., Fisher, H.L., Russo, M., Murray, R.M., Stilo, S.A., Wiffen, B.D., O'Connor, J.A., Falcone, A.M., Pintore, S.M., Ferraro, L., Mulè, A., La Barbera, D., Morgan, C., Di Forti, M., 2014. Failure to find association between childhood abuse and cognition in first-episode psychosis patients. Eur. Psychiatry 29 (1), 32-35.

Stilo, S.A., Di Forti, M., Mondelli, V., Falcone, A.M., Russo, M., O'Connor, J., Palmer, E., Paparelli, A., Kolliakou, A., Sirianni, M., Taylor, H., Handley, R., Dazzan, P., Pariante, C.M., Marques, T.R., Zoccali, R., David, A., Murray, R.M., Morgan, C., 2013. Social Disadvantage: Cause or Consequence of Impending Psychosis? Schizophr. Bull. 39 (6), 1288-1295. 
Stilo, S.A., Gayer-Anderson, C., Beards, S., Hubbard, K., Onyejiaka, A., Keraite, A., Borges, S., Mondelli, V., Dazzan, P., Pariante, C.M., Di Forti, M., Murray, R.M., Morgan, C., 2017. Further evidence of a cumulative effect of social disadvantage on risk of psychosis. Psychol. Med. 47 (5), 913-924.

Trotta, A., Di Forti, M., Mondelli, V., Dazzan, P., Pariante, C.M., David, A., Mulè, A., Ferraro, L., Formica, I., Murray, R.M., Fisher, H.L., 2013. Prevalence of bullying victimisation amongst first-episode psychosis patients and unaffected controls. Schizophr. Res. 150 (1), 169-175.

Trotta, A., Di Forti, M., lyegbe, C., Green, P., Dazzan, P., Mondelli, V., Morgan, C., Murray, R.M., Fisher, H.L., 2015. Familial risk and childhood adversity interplay in the onset of psychosis. BJPsych Open 1 (1), 6-13.

Trotta, A, Iyegbe, C., Di Forti, M., Sham, P.C., Campbell, D.D., Cherny, S.S., Mondelli, V., Aitchison, K.J., Murray, R.M., Vassos, E., Fisher, H.L., 2016a. Interplay between Schizophrenia Polygenic Risk Score and Childhood Adversity in FirstPresentation Psychotic Disorder: A Pilot Study. Walss-Bass C, ed. PLoS One 11 (9), e0163319.

Trotta, A., Murray, R.M., David, A.S., Kolliakou, A., O'Connor, J., Di Forti, M., Dazzan, P., Mondelli, V., Morgan, C., Fisher, H.L., 2016b. Impact of Different Childhood Adversities on 1-Year Outcomes of Psychotic Disorder in the Genetics and Psychosis Study. Schizophr. Bull. 42 (2), 464-475.

Trotta, A., Iyegbe, C., Yiend, J., Dazzan, P., David, A.S., Pariante, C., Mondelli, V., Colizzi, M., Murray, R.M., Di Forti, M., Fisher, H.L., 2018. Interaction between Childhood Adversity and Functional Polymorphisms in the Dopamine Pathway on First-Episode Psychosis. Schizophr. Res. S0920-9964 (18), 30199-30193.

Vassos, E., Di Forti, M., Coleman, J., lyegbe, C., Prata, D., Euesden, J., O'Reilly, P., Curtis, C., Kolliakou, A., Patel, H., Newhouse, S., Traylor, M., Ajnakina, O., Mondelli, V., Marques, T.R., Gardner-Sood, P., Aitchison, K.J., Powell, J., Atakan, Z., Greenwood, K.E., Smith, S., Ismail, K., Pariante, C., Gaughran, F., Dazzan, P., Markus, H.S., David, A.S., Lewis, C.M., Murray, R.M., Breen, G., 2017. An Examination of Polygenic Score Risk Prediction in Individuals With First-Episode Psychosis. Biol. Psychiatry 81 (6), 470-477.

World Health Organization. 1992a. The ICD-10 Classification of Mental and 
Behavioural Disorders: Clinical Descriptions and Diagnostic Guidelines.

Geneva: World Health Organization.

World Health Organization. 1992b. Schedules for Clinical Assessment in

Neuropsychiatry (SCAN). Geneva: World Health Organization.

Zajkowska Z.,and Mondelli V., 2014. First-episode psychosis: an inflammatory state? Neuroimmunomodulation, 21(2-3):102-108 